\title{
O adoecer e morrer de mulher jovem com câncer de mama
}

\author{
Falling ill and dying of a young woman with breast cancer
}

Janderléia Valéria Dolina ${ }^{1}$

Roseney Bellato ${ }^{1}$

Laura Filomena Santos de Araújo ${ }^{1}$

${ }^{1}$ Programa de PósGraduação, Faculdade de Enfermagem, Universidade Federal de Mato Grosso (FAEN/UFMT). Av. Bosque da Saúde 635, Bosque da Saúde. 78.050-070 Cuiabá, MT.

jandidolina@yahoo.com.br

\begin{abstract}
This study focused on the experience of a young woman with breast cancer and sought to understand the progression of her falling ill, dying and death based on the significance attributed to the events of her life. It concentrates on the idea that one dies from how one has lived and in the way that a new meaning is attributed to this life over the course of time. It is qualitative research that is presented as a situational study that enabled the construction of Beth's Life Line using her Life History in which, judging from her narratives, events considered significant by her and that confirmed her way of living, stand out and are reflected in her death. Besides the detailed description of how the interview meetings occurred, it also discusses two central categories of the study, called "Ebbing of life - the small deaths experienced by Beth" and "Beth living out her dying and death." The study emphasizes the need for the health professionals to assume responsibility for a kind of care that does not only seek a cure, but also focuses on the human dimension, aiming to ensure well-being and maintenance of life, while this is still possible.
\end{abstract}

Key words Death, Breast cancer, Family relationships, Health care
Resumo O estudo teve como foco a vivência de mulher jovem com câncer de mama e objetivou compreender o adoecer, o morrer e a morte dela, a partir dos sentidos atribuídos aos eventos de sua vida. Apóia-se na ideia de que se morre a partir do que foi vivido e no modo com que este vivido vai sendo ressignificado ao longo do tempo. Trata-se de pesquisa qualitativa que se configura como um estudo de situação, o qual permitiu construir a Linha da Vida de Beth através do emprego de sua História de Vida em que se destaca suas narrativas, eventos considerados, por ela, marcantes e que conformaram o seu modo de viver e, nele, o morrer. Além da descrição minuciosa de como se deram os encontros de entrevista, também discute-se duas categorias centrais do estudo, denominadas de "Morrer a vida - as pequenas mortes vivenciadas por Beth" e "Beth vivendo seu morrer e morte”. O estudo enfatiza a necessidade dos profissionais da saúde tomarem para si a responsabilização por um modo de cuidado que não vise tão somente a cura, mas que tenha como foco a dimensão humana com o objetivo de prover o bem estar e a manutenção da vida, enquanto esta for possível. Palavras-chave Morte, Câncer de mama, Relações familiares, Cuidados à saúde 


\section{Introdução}

Este estudo apoia-se na ideia de que se morre a partir do que foi vivido e que este vai sendo ressignificado ao longo do tempo. Toma por base a compreensão da história de vida de uma mulher jovem com câncer de mama, cujos eventos considerados marcantes conformaram o seu modo de viver e, nele, o morrer. Entendemos que essa ressignificação do vivido se torna mais intensa na experiência de adoecimento por câncer, frente às modificações que provoca, obrigando à produção de rearranjos para a manutenção do cotidiano ${ }^{1}$.

Também outros elementos estão imbricados na possibilidade concreta de morte, trazendo estigmas e medos, suscitando pavor, vergonha e expondo a pessoa a sua fragilidade e finitude. Acresce-se a este sofrimento a necessidade de se afastar de suas atividades rotineiras, as possíveis mutilações e a dor que enfrentará ao longo do tratamento ${ }^{2}$.

$\mathrm{Na}$ situação específica deste estudo a ressignificação da existência da jovem mulher se ancorou em um encadeamento de 'pequenas mortes', às quais o diagnóstico de câncer e o processo de adoecimento, morrer e morte vieram se juntar. Tomamos a concepção de 'pequena morte' a cada uma das 'perdas' vivenciadas ao longo da vida; ou seja, "são experiências que nos fazem pensar na morte que, embora não tenha ocorrido concretamente, trazem muitos atributos que são comumente a ela associados, como dor, ruptura, interrupção, desconhecido e tristeza”’.

Entendemos que discutir sobre a morte não significa adquirir um gosto mórbido pelo viver, nem assumir uma perspectiva negativa diante das situações ${ }^{4}$. Trata-se de tomar como reflexão uma dimensão que conforma e dá sentido à nossa existência, mas, que também é conformada e significada a partir daquilo que foi vivido por nós. Essa compreensão pode oferecer a nós, profissionais de saúde, elementos essenciais para conceber possibilidades de cuidado à pessoa ao longo deste processo, resgatando o elemento humano, essencial à perspectiva do cuidado à pessoa e não apenas ao corpo biológico ${ }^{5}$.

Assim, compreender a vida da pessoa com câncer aponta para a necessidade de discutir sentimentos, compartilhar suas dores, tristezas e preocupações, buscando minimizar as tensões de uma situação permeada por incertezas e temores quando a finitude se torna próxima. Implica em ter sensibilidade para olhá-la como alguém que tem consciência da situação em que se encontra e que precisa de cuidados para sua esfera existencial e não somente para seu corpo físico ${ }^{6}$.

A cultura ocidental moderna, fortemente assentada no paradigma científico e no modelo biomédico, produz uma radical separação entre o doente e sua doença, assim como entre sua vida e sua morte ${ }^{7}$. Neste estudo evidenciamos a importância de ouvir a pessoa contar-se, buscando compreender o todo de sua existência e as ressignificações feitas ao longo do tempo dos eventos por ela vividos.

Concordamos que a formação dos profissionais de saúde tem se calcado nos procedimentos técnicos em detrimento de uma formação humanista que possa lhes dar respaldo para incorporar tanto a tecnologia e o saber acumulados ao longo da história quanto o sentido humano ao se lidar com emoções e cuidado ${ }^{7}$. Neste sentido, necessário se faz pensar em modos de estar junto de fato e por inteiro no cuidado da vida e para a vida, mesmo em situações de finitude.

Diante do exposto, objetivamos compreender o adoecer, o morrer e a morte de mulher jovem com câncer de mama, a partir dos sentidos por ela atribuídos aos eventos de sua vida.

\section{Método}

Trata-se de pesquisa qualitativa que se configura como um "estudo de situação" vida de Beth, mulher de 34 anos com câncer de mama e fora de possibilidades terapêuticas de cura, vivenciando sua finitude, sendo este o critério de sua inclusão no estudo. A compreensão da situação e contexto peculiares de sua vida, bem como de sua família, permitiu-nos traçar algumas inferências mais abrangentes a partir da análise desta microrrealidade ${ }^{9}$, dando relevo às sinuosidades das relações de diversas ordens estabelecidas durante sua vida, particularmente àquelas de intensa carga afetiva.

Beth foi contatada através de uma Instituição de Saúde especializada em oncologia e conveniada ao Sistema Único de Saúde localizada na mesma cidade em que residia com sua família. $\mathrm{O}$ contato iniciou-se após aprovação formal da Diretoria da instituição e, além de Beth, participaram do estudo suas duas filhas adolescentes, Beatriz e Bruna, de 15 e 16 anos, respectivamente, e Dona Carlota, sua mãe.

Para a recolha de dados empregamos a História de Vida (HV), que nos possibilitou a compreensão profunda do seu vivido, a partir do estabelecimento de uma relação de confiança entre 
nós ${ }^{10}$. Esta relação foi sendo construída ao longo de nove (09) encontros de entrevista que ocorreram no período de outubro de 2011 a maio de 2012. Estes se deram, em sua maioria, na casa de Beth, visto que ela já se encontrava acamada, debilitada e com dificuldade respiratória. Também ocorreram dois encontros em um hospital especializado no tratamento oncológico onde ela realizava acompanhamento médico, já em fase final do seu processo de morrer.

O corpus do estudo compôs-se de 86 páginas em documento Word resultante da transcrição, na íntegra, das gravações recolhidas nas conversas com Beth, bem como, com suas filhas e sua mãe, além das observações de campo. Procedemos inúmeras leituras desse material da História de Vida de Beth, do qual alguns acontecimentos trazidos por ela e reiterados ao longo dos demais encontros foram "saltando aos nossos olhos".

Buscamos conferir visibilidade às significações trazidas por Beth ao seu vivido, bem como suas implicações no modo de experienciar o processo de morrer e a morte. Assim, este estudo se apresenta um pouco diferenciado, pois optamos por descrever, em uma categoria inicial, a aproximação com ela e sua família e seu modo particular de contar-se a nós. Construímos, também, um desenho analítico denominado a "Linha da vida de Beth", no intuito de que este a representasse em sua essencialidade de ser humano. Neste desenho, elencamos os principais trechos de sua narrativa, aqueles que para nós, sintetizavam momentos significativos de sua história. Posteriormente, organizamos outras duas categorias nas quais discutimos estes trechos alicerçados no modo de viver de Beth e em sua experiência de sua finitude.

Os preceitos éticos em pesquisa foram integralmente respeitados. As pessoas aqui citadas, bem como as instituições, tiveram suas identidades preservadas através do uso de nomes fictícios. A pesquisa matricial à qual este estudo se vincula foi aprovada pelo Comitê de Ética do Hospital Universitário Julio Müller, que também autorizou entrevistas com sujeitos de 05 a 18 anos.

\section{Resultados e discussão}

\section{Aproximando-se da história de Beth e desenhando sua Linha da Vida}

Conhecemos Beth em outubro de 2011, uma mulher de 34 anos, que havia recebido diagnóstico de câncer de mama em 2006 e, para tratá-lo, realizou inúmeras seções de radioterapia e quimioterapia, cirurgias e outros procedimentos para alívio de sintomas. No dia em que nos encontramos ela já sabia que não havia possibilidade de cura para sua doença, pois se tratava de um tipo de câncer de mama agressivo, já com metástase para pulmão e ossos.

Quando chegamos a sua casa, ela estava no quarto, deitada na cama, com facies de dor e dificuldade para respirar, mostrando-se gemente e ofegante. O seu estado físico nos preocupou bastante, deixando-nos receosas de manter a entrevista, pois poderíamos estar aumentando seu incômodo e desconforto pelo esforço de rememoração e fala. Colocamo-nos a disposição para agendar o encontro para ocasião mais propícia, porém Beth disse que queria conversar conosco.

Assim, tão logo começou a falar, as nossas incertezas sobre a adequação de estar ou não ali se dissiparam, pois ela demonstrava uma necessidade, quase afoita, de contar-nos sobre sua vida e sua história de adoecimento. Começou a narrar sua vivência a partir de nossa pergunta inicial: "Conte-nos como se deu a sua experiência de adoecimento, desde o diagnóstico até os dias de hoje”.

Ao longo de quase duas horas, Beth falou de modo contínuo, dando-nos a impressão de estarmos ouvindo a narração de um trecho de livro, já lido diversas vezes. Apesar de ser a "sua história" que estava sendo por ela contada, Beth parecia se posicionar como narradora dos fatos e não como protagonista das situações. Assim,

Despedimo-nos e fomos embora com a sensação de que havíamos ouvido uma história ensaia$\mathrm{da}$, pois Beth manteve o mesmo tom de voz na maior parte do tempo. Emocionou-se algumas vezes, mas retomava o assunto sem grandes interferências (Observações de campo - 24/10/2011).

Percebemos certa externalidade de Beth ao narrar sua experiência de vida e, nela, a de adoecimento, como se isso tivesse acontecido em um plano diferente daquele que estava sendo vivido por ela naquele momento. Em meio a sua história ela falou do ex-marido, se referiu ao seu padrasto dizendo da relação conturbada, mas sempre com certa superficialidade, como que separando aquilo que era importante para sua vida daquilo que considerava ser possível sabermos. Talvez isso tenha acontecido pelo fato de termos nos apresentado como enfermeiras, o que pode a ter levado a considerar que estivéssemos ali para investigar os sinais e sintomas clínicos de sua doença e de seu tratamento, posição geralmente assumida pelos profissionais de saúde ao se aproximarem da pessoa doente. 
Tínhamos claro que nossa intenção não era de que Beth nos contasse a história da doença, que poderíamos encontrar em seu prontuário na instituição de saúde em que estava sendo acompanhada. Indubitavelmente, intencionávamos nos aproximar de seu modo de vida para então, compreender sua experiência de adoecimento e finitude. Assim, concluímos que aquele questionamento inicial feito a ela não respondia ao que precisávamos compreender, pois o direcionamento não deveria ser para a doença e, sim para sua vida. Por isso, voltamos à sua casa, e, ao invés de perguntarmos sobre o diagnóstico e o período de adoecimento, perguntamos sobre sua vida, sobre sua infância e sua família.

Percebíamos que as situações por ela experienciadas no cotidiano se constituíam no substrato da vivência do adoecimento por câncer, visto que é a partir do viver e no modo de viver que o adoecer se reveste de sentido. Nossa atitude, então, era de atenção ${ }^{11}$ a essas situações, sem diferenciá-las em antes e após o adoecimento, mas tomando-as como a totalidade do viver.

Refocamos nosso olhar para a história de vida de Beth, retomando o nosso pressuposto de que para compreender a vivência do processo de morrer não basta entender o adoecimento. Esse reposicionamento fez com que ela também se despisse da história, aparentemente ensaiada, sobre seu adoecimento e nos contasse sua vida, assinalando o que nela considerava importante.

A postura de escuta, o comprometimento de respeito por sua história e a constante preocupação com seu bem estar, fez com que entre nós se estabelecesse uma relação de confiança. Essa relação permitiu o adensamento da história, alcançando diferentes graus de profundidade ao longo do tempo.

Concordávamos que nossa posição não era de "gravador humano" que se limita a registrar o dito, mas de alguém que reagia a uma gargalhada e um soluço, atento ao todo da interação, seja por meio da fala ou de expressões não verbais, silêncios e intensidade de voz. Na HV, é necessário que a pessoa entrevistada ocupe o lugar central da relação. Ao "se contar", ela se conta a outra pessoa numa determinada circunstância e condicionada a certa construção seletiva da memória; também o pesquisador se posiciona nessa interação com uma intencionalidade, definida pelos objetivos de sua própria investigação ${ }^{12}$.

Percebemos que Beth, apesar de manter a cadência de sua narrativa com certo distanciamento afetivo, emocionava-se ou mudava o tom de voz ao rememorar alguns dos acontecimentos por ela vividos. Às vezes 'se perdia' em suas memórias, mas retomava ao mesmo acontecimento que gerou a divagação; também um mesmo acontecimento relatado em determinada fase de sua vida, era retomado em outra, mostrando-se marcante para seu desfecho, num movimento em espiral.

Essa compreensão reforçava-nos que a vida não é linear e nem vivida de forma sequenciada em momentos distintos, mas o entrelaçamento dos acontecimentos vividos se mostrava bastante marcante. Alguns acontecimentos, embora afastados temporalmente, guardavam vinculação estreita entre si, como se fossem reverberações, em um constante movimento, mostrando que "a vida se constrói no movimento de sua destruição, e se organiza no movimento de sua desorganização"13.

Após o término dos encontros de entrevista, e buscando entender a complexidade dessa desorganização/reorganização permanente que constitui a vida, surgiu a necessidade de construir um desenho no qual pudéssemos representar, imageticamente, a vida de Beth e, nela, aquilo que nos pareceu se constituir em suas 'pequenas mortes'. Para isso, selecionamos trechos das narrativas que nos 'saltaram aos olhos' e fomos dispondo em uma linha reta, sequenciando-as, cronologicamente, do seu nascimento à sua morte.

Todavia, percebendo que não expressava o que havíamos apreendido das narrativas de Beth, refizemos o desenho buscando fugir da 'cronologização', mas apoiando-nos nas 'escansões' oferecidas por ela. Essa ideia nos remetia à compreensão de que o "tempo do vivido" não é contínuo, uniforme, linear, segmentável; mas, descontínuo e não uniforme, cuja marcação é mais afetiva do que cronológica, desenhando-se em espirais ${ }^{14}$.

Elaboramos, então, um desenho da linha da vida em espiral, de modo que cada volta ou circunvolução correspondesse a um acontecimento marcante trazido por Beth. Porém, embora a espiral se mostrasse mais representativa do que a linha reta, ainda não podia expressar o vivido por ela. As recorrências de situações de sofrimento e as reverberações que produziam em sua vida não se mostravam presentes nas circunvoluções da espiral, pois, ainda que retomasse algo do passado para influenciar o presente, não transmitia a ideia da profunda imbricação e dos entrelaçamentos que existiam entre as muitas situações vividas.

Ao mesmo tempo em que, solidárias com a história de vida de Beth, que se alicerçava em situações de muito sofrimento, ansiávamos por oferecer-lhe uma imagem bela e o mais próxima 
àquilo que nos foi possível compreender de seu vivido. Concluímos, então, que a imagem de uma flor, a 'rosa', poderia ser usada para apresentar sua história de vida e, nela, o adoecimento e a morte. A rosa traz implícita em seu formato aquilo que os matemáticos e filósofos, desde a antiguidade, denominam de "Razão Áurea" - a disposição de suas pétalas se faz em forma de uma espiral que se separam por ângulos que podem ser medidos e quantificados, possuindo coerência e correspondência entre si, numa lógica matemática, representando a mais agradável proporção entre duas medidas ${ }^{15}$.

Assim, com a rosa mantivemos a ideia inicial da espiral representada pela implantação sequenciada das pétalas em torno do seu receptáculo. Também, a ideia de acontecimentos que guardam vinculações estreitas entre si, mesmo que afastados temporalmente, pode ser expressa pela dobradura delicada de cada pétala e sua sobreposição umas às outras, conforme vão desabro- chando, oferecendo apoio e sustentação numa relação mútua de dependência e influência, como os eventos da vida de Beth. Sintetizávamos na rosa (Figura 1) a imagem da Linha da Vida de Beth, tanto no sentido ético de fidelidade ao que ela nos narrou, quanto na percepção estética, trazendo a forma perfeita da flor para expressar esse vivido único e complexo.

Com isso, podemos afirmar que a linha da vida só é possível de ser construída a partir de certo modo de aproximação com a pessoa e que cada uma tratará elementos diferentes de suas vivências e sentimentos que lhe são próprios. Essa linha segue, assim, uma diretriz na sua construção - os eixos de sentido do vivido aos quais o pesquisador busca dar destaque.

Passaremos a descrever os inúmeros acontecimentos na vida de Beth que estiveram relacionados à ideia de 'pequenas mortes', pois, segundo suas narrativas, representaram grandes perdas e muito sofrimento.

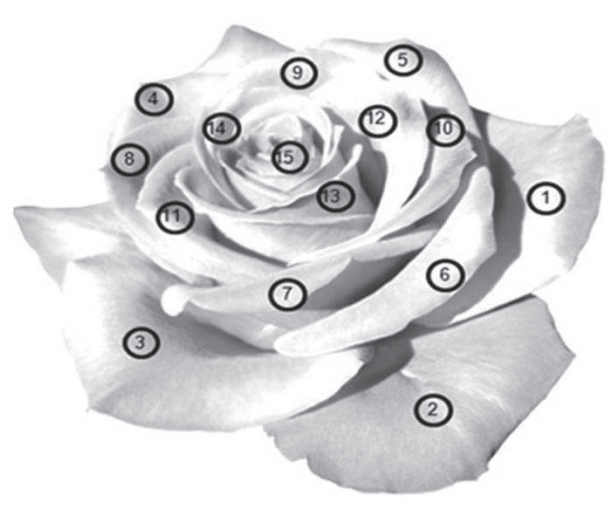

1- [...] até os 6 anos eu morei com minha avó. Ela faleceu eu tinha 6 anos.

2- Até os 12 anos eu morava trabalhando. Aí eu voltei prá casa da minha mãe. Aí começou a conturbação novamente. Meu padrasto. Aí aconteceu aquele imprevisto, eu saí de casa.

3- [...] cada dia eu ficava numa casa. Todo dia uma hora dessa eu tava caçando lugar pra mim ficá. Quando num achava nenhum, eu ia pro viaduro... dos indigente né?

4- Depois que fiquei sabando que tentô mexê cas menina, daí eu chutei ele daqui de casa. Mesmo morrendo de amor por ele... Minhas filha é mais importante do que, do que tudo pra mim. Aí eu entrei com divórcio também.

5- [...] dois meses eu passei muito nervoso. A discussão ca minha mãe, meu padrasto... tudo, meu esposo... Aí evoluiu, de repente apareceu aquele caroço e foi crescendo, crescendo [...] Aí deu que era ... câncer né... (silêncio) Aí começô o tratamento [...]
6- $\mathrm{O}$ que tava mais me matando mesmo era ele (o marido). Eu ficava boa, ia estabilizando, eu passava raiva o câncer voltava... Eu já tava bem, meus exame tava tudo bem, não tinha caroço nenhum, aí vinha meu marido. Parecia que ele tava querendo me matá mesmo $[\ldots]$

7-É. E na última ele feiz... rapô até o osso, bem radical mesmo [...] Aí deu no pulmão, deu em várias outras partes (metástases) [...]

8- O tratamento é muito agressivo... As primeiras quimio, em 14 dias eu já tava sem nenhum cabelo. Eu ficava 15 dias em cima da cama vomitando $[\ldots]$

9- [...] eu num dô conta, nem de andá daqui ali eu num dô conta (chorando). Eu tenho que tá segurandu em alguém, entendeu? [...] Quem antes era a cabeça da casa era eu, agora num é eu, é elas (suas filhas). O papel inverteu. Eu num dô conta mais de fazê o que eu fazia antes. A responsabilidade ficô em cima delas (chorando)

10- Aí eu fiquei ruim, ruim. Meus exame tudo tá dando derrame pleural, derrame pleural... Aí desde então, quando eu vim (do hospital), eu numca mais me levantei, eu num ando sozinha, num consigo fazê nada [...]

11- [...] Que otro meu médico de quimio [...] Falô que num podia fazê mais nada comigo, num queria fazê mais nada. Pô, ia esperá Deus chegá, esperá a morte chegá? Pra ele num tinha mais jeito [...]

12- Aí eu vo fica deste jeito que ceis tão vendo aqui. E cada dia eu to assim, eu to esperando só no Senhor. Porque o Senhor é todo poderoso, Ele já fez tantos milagre, tantas cura que o Senhor já fez, entendeu?

13- [...] dá tistimunha pra outras pessoas, eu tenho vontade na hora que eu sai dessa situação aqui. Então eu falei pro Senhor que eu me propunho a fazê isso, sê testemunho vivo pra Ele, pra contá.

14- “minha mãe morreu”(Observação de campo)

Figura 1. Linha da vida de Beth. 


\section{Morrer a vida}

- as pequenas mortes vivenciadas por Beth

Preponderantemente, estudos têm tratado dos aspectos biológicos na gênese do câncer, da função imune e vigilância orgânica em relação às células cancerosas. Também têm sido foco de pesquisas os afetamentos que o câncer de mama produz na vida da mulher após o seu diagnóstico. No entanto, começa a ser estudado o modo de ser e viver da mulher na ocorrência do câncer, dando-se ênfase a uma possível correlação entre a defesa orgânica e os estados psicoemocionais, apontando que "determinados estilos de personalidade, tais como negação, repressão, evitação e dificuldades em externar emoções ou conteúdos internos, cursam com função imune menos ativa" na ocorrência do câncer ${ }^{16}$.

Nesse sentido, a história de Beth nos pareceu bastante emblemática dessa relação, não no que se refere ao seu aspecto biológico; mas, sim, quanto à dimensão psicoafetiva e familiar de sua vida e de sua morte por câncer de mama. Chamounos a atenção, desde nosso primeiro encontro com ela, as narrativas permeadas pela palavra 'morte' ao se referir não ao câncer, propriamente dito, como seria de se esperar, mas à situações por ela vividas. Estas foram apresentadas com sentimentos de perda em momentos importantes para ela, tanto em relação às pessoas quanto a eventos estruturantes de sua personalidade e feminilidade, desde tenra idade.

Logo após o nascimento, Beth foi morar com a avó materna, ali permanecendo até os seis anos de idade. Seu pai tinha outra família, com filhos e esposa e não reconheceu sua paternidade (Figura 1, narrativa 1). Quando, aos seis anos de idade, sua avó morreu (Figura 1, narrativa 2), ela foi morar com a mãe, Dona Carlota, que havia se casado com outro homem, Genésio. Mas, conforme Beth nos narrou, o padrasto não gostava dela e tentava impedir sua mãe de vê-la, vivendo em um ambiente conturbado emocionalmente. Entre os 10 e 12 anos saiu da casa da mãe, expulsa pelo padrasto, e foi morar em casa de família como babá, em troca de abrigo e comida. Aos 12 anos retornou para a casa da mãe, mas, sofreu uma situação de estupro, segundo ela, a mando do padrasto. Ao nos narrar este fato, Beth usou de um tom de voz baixo, e limitou-se a chamar este acontecimento traumático de aquele imprevisto (Figura 1, narrativa 3). Diante disso saiu novamente da casa da mãe e passou a trabalhar em troca de casa para dormir e comida; e, até os dezesseis anos morou em muitos lugares, com famílias ou com conhecidos ligados a igreja que frequentava. Narrou que, quando não encontrava lugar onde ficar ou dormir, permanecia na rua, embaixo de viadutos ou na rodoviária (Figura 1, narrativa 4).

Percebemos que, após os seis anos, quando a avó morreu, a ausência de uma estrutura familiar com certa estabilidade marcou, de forma intensa, as narrativas de Beth, que passou a viver sem a referência de um lar, como "lugar de pertencimento" físico e afetivo. Sobre isso, lembramos a imagem da casa como a metáfora do ninho ${ }^{17}$, ou seja, 'o lugar' do aconchego que oferece proteção contra os sofrimentos da vida. Contudo, para Beth, grande parte de sua infância passou-se sob a sombra da falta de referência de uma 'casa-ninho', trazendo a imagem da intimidade perdida. Também a série de rompimentos de vínculos afetivos levaa à perda de sua referência de pertencimento a um lar e a uma família.

Cada uma dessas sucessivas ocorrências de perdas emocionais, psicológicas e de lugar de pertencimento que Beth viveu se configuraram como pequenas mortes, pois entendemos que tais experiências afetaram, de modo intenso e dramático, sua formação como pessoa. Pertencer a um lugar e estabelecer relações de interdependência com outros é dimensão constitutiva da formação da criança, sendo que a sua ausência pode causar angústias, medo, solidão e falta de segurança para lidar com problemas na vida adulta. A família é o "núcleo essencial de constituição do sujeito" à medida que esteja inserida nesta dinâmica perpassada por desejos, lugares psíquicos, identificações, ambivalências, posições hierárquicas, construções imaginárias, mitos e historicidade ${ }^{18}$.

Aos 16 anos Beth mudou de cidade e, ainda trabalhando em casa de uma família, conheceu um homem, com 30 anos, com quem passou a morar, sendo que, ao falar dele, destacou o fato de ele não beber e nem fumar, o que lhe passava uma imagem de respeito. Alegou também que, durante os primeiros meses, morou com ele, mas não fazia essas coisas, referindo-se a manter relações sexuais, pois tinha trauma, tinha medo. Entretanto, acabou por engravidar e, logo em seguida, descobriu que o homem a traia. Não podendo retornar à casa da mãe devido ao padrasto e não tendo para onde ir, passou, novamente, a peregrinar por espaços temporários, até mesmo na rua ou na rodoviária.

Quando teve sua filha, Beatriz, foi acolhida por curto tempo na casa da irmã do pai da criança, mas ele não quis assumir a paternidade. Voltou a ter que morar na rua, agora com o bebe recém- 
nascido. Após algum tempo, Beth passou a morar com uma amiga, ainda que em situação precária, e, nesse ínterim, conheceu o irmão dessa amiga que resolveu assumi-la, como companheira. No entanto, era alcoólatra e um dia ela o encontrou em uma casa de prostituição. Assim, saiu de casa, juntamente com uma filha e novamente grávida.

Beth procurou outro lugar para morar e conseguiu emprego na casa de uma família onde teve sua filha, Bruna. Pouco tempo depois, conheceu Gerson, que, a princípio, parecia ter um comportamento que ela considerou respeitoso. Casou-se com ele, sendo que o casamento durou 15 anos; porém, ao adoecer por câncer de mama, em 2006, intensificaram-se problemas conjugais que já existiam e, inclusive, sofreu traições. Ela nos narrou, também, que seu marido havia tentado violentar sexualmente suas filhas, situação que a levou a decidir pelo divórcio (Figura 1, narrativa 5).

As figuras masculinas com as quais Beth se relacionou ao longo de sua vida apareceram em suas narrativas frequentemente vinculadas a situação de violência e traição, numa circularidade de vivências de tristeza e dor. Percebemos que, para ela, há um fatalismo nesse círculo vicioso, o que reforça a concepção da banalização, minimização, negação e naturalização das situações de violência contra a mulher ${ }^{19}$.

No decorrer da conversa com Beth pudemos perceber detalhes do relacionamento conflituoso que teve com o marido e a importância dessa relação em sua vida e nos sentidos que atribuiu ao câncer de mama. Foi nessa relação, mais do que em qualquer outra ao longo de sua vida, que ancorou a maior parte de suas rememorações e referências de afetividade e sofrimento. Assim, defrontamo-nos com o paradoxo de ser esse homem aquele por quem eu tinha um amor tão grande por esse meu marido, também era por quem eu morria por causa desse monstro. Também aquele que tava mais me matando mesmo era ele [...] parecia que ele tava querendo me matá mesmo, pra ficá cas minhas coisas (Figura 1, narrativa 7), referindo-se ao fato de que, quando se sentia melhor fisicamente, aconteciam brigas e discussões entre eles e, por isso, ela voltava a piorar.

O divórcio, aparentemente, provocou a ruptura desse círculo vicioso de sofrimentos. Todavia, pudemos perceber a permanência da mágoa e da dor permeando sua vida com relação ao exmarido, pois, inúmeras vezes em sua narrativa, ela retomou o relacionamento, afirmando que ainda não o havia esquecido: [...] e eu to aí, daqui pra cá oh! Já sofri muito tempo. Num tira a pessoa, mesmo que a pessoa fez uma coisa errada, num tira a pessoa dum dia pro outro do coração da gente né? Foi muito difícil pra mim, nossa! (Beth).

A separação ou o divórcio se configuram, também, como uma pequena morte, uma morte em vida, pois o outro continua a existir, mas deixa de fazer parte do convívio, sendo necessário reelaborar essa perda para conseguir retomar o equilíbrio psicológico ${ }^{3}$.

A ressignificação da própria vida sem o outro se torna ainda mais difícil quando há baixa autoestima, baixa autoconfiança e vínculos afetivos frágeis. A dificuldade desse movimento de ressignificação é potencializada pela situação de adoecimento de Beth, que a deixou ainda mais frágil e com poucas perspectivas de assumir as rédeas de sua vida. Novamente desenha-se o círculo reforçador de negatividades, perpetrando agravamento em sua doença, trazendo a morte não apenas de sua esperança de cura, mas também de manutenção de sua relação amorosa.

Tendo nos aproximado das "pequenas mortes" vividas por Beth ao longo de sua vida, passaremos a apresentar, de modo mais centrado, seus últimos cinco anos, período entre o diagnóstico de câncer de mama e sua morte, quando vivenciou seu processo de finitude, porém sem deixar de fazer referência ao todo de seu vivido.

\section{Beth vivendo seu morrer e morte}

Ao nos contar sua história de vida e adoecimento, Beth apontou como causa do aparecimento do câncer de mama a sua situação familiar e afetiva; localizou, inclusive, os últimos meses como se fossem de grande tensão e, por isso, com o poder de ter desenvolvido a doença. Nas suas palavras,

[...] dois meses eu passei muito nervoso, muito nervoso mesmo. A discussão ca minha mãe, meu padrasto... tudo, meu esposo... Aí evoluiu, de repente apareceu aquele caroço e foi crescendo, crescendo, crescendo [...] Aí deu que era... câncer, né? [silêncio]... Aí começô o tratamento [...] (Beth).

Beth não apenas traçou a estreita relação entre o câncer e esses estados emocionais que viveu, como também ao crescimento rápido e voraz do tumor. Reforça, assim, a concepção presente de que o câncer advém de sentimentos dolorosos, estados de depressão ou de perdas, manifestos em pessoas que se posicionam como perdedores na batalha da vida ${ }^{20}$.

Em suas narrativas Beth empregou poucas vezes a palavra "câncer" e, quando o fazia, geralmente era em tom baixo de voz. Algumas vezes se referiu a ele como uma doença dessa uma doença tão terrí- 
vel; já em outras, comparava-o a uma gripinha qualqué. Entretanto, também afirmou que só que é difícil cê sabê que tá com uma doença dessa. A primeira coisa que cê imagina é 'pô, cê vai morrê.'

Ainda que sejam raros os estudos acerca da possibilidade das situações de vida influírem na ocorrência do câncer, para Beth seu tumor não apenas resultou dos sofrimentos emocionais que vivenciava junto à família e ao esposo; como também sua recrudescência se deve a esses sofrimentos, particularmente aqueles advindos da sua relação conjugal (Figura 1, narrativa 6). A traição sofrida do marido põe novamente em movimento a circularidade das situações negativas no campo afetivo por ela experienciadas ao longo da vida.

Se, adoecer por câncer é algo traumático para qualquer ser humano, vivenciar esse adoecimento em meio a perdas afetivas importantes tornase insuportável (Figura 1, narrativas 7). Com isso, podemos concordar que a desestruturação advinda de situações de divórcio e abandono, bem como atitudes de traição e deslealdade podem deixar marcas afetivas que prejudicam o enfrentamento do adoecimento ${ }^{21}$.

Após cinco anos de tratamento intenso, cirurgias repetidas e vários esquemas de quimioterapia e radioterapia, Beth afirmou: o que mais me mata mesmo não é câncer, mas o tratamento. Suas narrativas nos falam de mutilação em seu seio, dores e medicações que lhe causaram náuseas, vômitos e a perda dos cabelos (Figura 1, narrativas 8 e 9). Podemos perceber que as reações adversas das terapêuticas podem causar tamanho sofrimento e dor física e emocional que acabam por receber o status de doença. Nessa situação, o tratamento se torna uma fase tão difícil quanto a própria descoberta da doença ${ }^{22}$.

Percebemos sentimentos paradoxais expressos por Beth em relação à sua possibilidade concreta de morte física e à crença na cura através da religiosidade (Figura 1, narrativas 10 e 11). No bojo dessa situação de agravamento das manifestações de sua doença e intensificação do tratamento, ocorreram desavenças entre suas filhas e sua mãe com repercussões para esse momento de maior dependência de Beth em relação ao cuidado familiar, assim como a decisão médica de considerar sua situação como fora de possibilidades terapêuticas de cura (Figura 1, narrativa 12). Mas, ainda assim, ela reafirmava estar curada, conforme observado:

Beth afirmou novamente que acredita estar curada e que o que está sentindo são apenas os efeitos do tratamento e que tudo vai passar. Mencionou o quão mal ficou na semana anterior: eu parecia morta, suava frio, unhas roxas. Achei que eu ia morrer, aí passou. Beth repetiu ainda que sabe que está curada, mas que está muito cansada: eu queria uma forma de acabar com tudo isso (Observações de campo - 09/11/2011).

Nestes momentos, Beth negava a possibilidade de morrer, afirmando acreditar que Deus a tivesse curado e que o que ela estava sentindo eram os efeitos colaterais do tratamento, mas que iriam passar. Percebemos que a religiosidade dava sentido para seu sofrimento e possibilidade de morte próxima. Assim, ao mesmo tempo negava e afirmava a morte, mas sempre amparada por Deus, acreditando-se um milagre Dele por estar viva e crendo que assim iria permanecer.

Além da negação ou afirmação da morte física, em alguns momentos Beth vivenciava a barganha com a divindade ${ }^{23}$ (Figura 1, narrativas 13 e 14). Diante do sofrimento advindo do adoecimento e da proximidade da morte, Beth buscou transcender sua experiência, pois desejava, assim, encontrar uma explicação para a vida, apegando-se à esperança de cura:

[...] Mas, se eu to até aqui é que Deus tem um plano na minha vida [...] Eu creio eu vo vencê, sim. Deus falô que eu vo vencê, vo vivê. E eu creio na palavra Dele que eu vo vivê, então eu vo. Isso é só um período, uma prova que eu tenho que passá, entendeu? Então... e Ele é fiel pra cumpri. E Ele falô que eu vo vivê (Beth).

Beth comparou a experiência do câncer a uma missão, visto como uma tarefa a ser vivida para que ela pudesse alcançar um objetivo maior. $\mathrm{O}$ relacionamento com Deus e a fé proporcionavam a certeza de cura e faziam com que as dores e o sofrimento fossem, ao menos, suportados.

Estudo afirma a necessidade de compreender a espiritualidade e a fé das pessoas, pois, este é um sentimento arraigado na nossa cultura e tão importante quanto qualquer outro modo de enfrentamento. Nesse sentido, é necessário compreender que a dimensão espiritual ocupa lugar de destaque na vida e é imprescindível considerála no planejamento do cuidado ${ }^{24}$.

Diante da possibilidade de morte, Beth preocupava-se em deixar uma casa para suas filhas, afirmando a importância de ter um lugar para morar:

[...] porque eu suei tanto, isso aqui é patrimônio da minhas filha. Se eu vier a falecer minhas filha tão dentro da casa delas, que tudo uma baseé uma casa. Se cê tivé uma casa as otras coisas cê consegue, tendo saúde cê consegue e tudo isso aqui eu construí pra elas (Beth).

$O$ fato de não ter tido uma 'casa' como lugar de segurança e proteção durante a infância e ado- 
lescência marcou a vida de Beth, que buscou construir uma para deixar para suas filhas. Essa preocupação levou-a, em agosto de 2011, a deixar um documento registrado formalmente em cartório, em que expressa sua determinação de que, quando morresse, as filhas deveriam ficar sob a guarda de seu irmão mais velho, que é casado e tem um filho; para isso, todos deveriam habitar essa casa que legava para as filhas. Tomamos conhecimento deste documento através de conversa com sua mãe, depois que Beth morreu. Estudo mostra que, em virtude da morte estar bem próxima, a preocupação com os filhos torna-se intensificada, gerando aflição em uma espécie de perda de uma situação que não poderá ser vivida ${ }^{25}$.

Pudemos nos encontrar algumas vezes com Beth nos seus últimos dias de vida, quando ela precisou ser hospitalizada, sendo que Beatriz, sua filha, nos avisou por telefone: Vem pro hospital. Ela prescisa d vc. Mãe ta muito sem ar. Ta pedindo socorro 'axando' q vai morrer (07/12/2011- mensagem enviada via celular por Beatriz).

Quando lá chegamos, Beth estava agitada, com respiração agônica, transpirando e com olhos assustados. Permanecemos ao seu lado, procurando apoiá-la nesse momento tão difícil, empregando, na medida do possível, os conhecimentos como enfermeiras, mas, principalmente, a solidariedade humana.

[...] Eles querem me fazer dormir, me deram até um remédio pra dormir. Mas, se eu dormir, como que eu vou respirar? [...]. Perguntou-nos qual o jeito correto de respirar: Como que faz pra entrar mais ar? Beth mostrava, pela sua voz e seu olhar, uma agonia e um desespero que deixavam qualquer pessoa sem saber o que fazer. Estava muito agitada, como se estivesse em pânico (Observações de Campo - 07/12/2011).

Acalmá-la, ampará-la e dizer-lhe o que estava acontecendo, foram dimensões do cuidado possível, pela 'presença por inteiro na situaçãolimite'. O sono repousante que sobreveio à nossa conversa-silêncio mostrou o quanto o cuidadopresença foi efetivo naquele momento.

Beth morreu no dia seguinte e recebemos a notícia, também de sua filha Beatriz, via telefone. Beatriz demonstrou calma e tranquilidade em sua voz, o que nos fez pensar que, após este longo período de adoecimento, já era possível uma aceitação da morte. Ainda, ela nos falou sobre o funeral e quais seriam os horários para realização dos ritos de despedida, além de reiterar o desejo de que participássemos. Com isso entendemos que, de algum modo, a relação que se estabeleceu ao longo dos nossos encontros serviu de apoio e amparo, a Beth em seu morrer e, também a família ao vivenciar sua morte.

Assim, concordamos que embora não seja possível transformar a circunstância da morte é preciso transformarmo-nos e as nossas atitudes através da maneira de lidar e entender o processo de morte. Falar da finitude do ser humano, portanto, envolve falar não só dos aspectos técnicos da morte como fim das funções encefálicas, mas, principalmente, dos aspectos afetivos e emocionais, da tristeza, separação, saudade ${ }^{7}$.

\section{Considerações finais}

Ao compreender o processo de morrer e morte de Beth através dos sentidos por ela atribuídos à sua vida fomos tomadas de grande inquietação pela 'carga' de sofrimento que as narrativas traziam. No entanto, o estudo nos mostrou que se morre a partir do modo como se viveu e que as perdas, ou pequenas mortes, experienciadas ao longo da vida podem tornar-se superlativas ou serem ressignificadas diante da perspectiva de morte próxima.

Essa percepção nos parece importante para a sensibilização dos profissionais de saúde, de modo que possam se questionar sobre qual tem sido a capacidade efetivamente apoiadora de suas práticas no cuidado à pessoa e à família que vivenciam o morrer e a morte.

É preciso enfatizar a necessidade de assunção, por nós profissionais da saúde, de um modo de cuidado que não objetive tão somente a cura, mas que tenha como foco o bem estar e a manutenção da vida, enquanto esta for possível e do modo como possa ser vivida pela pessoa que morre. Além disso, embora essa perspectiva possa parecer paradoxal - cuidar para a vida enquanto a pessoa caminha para a morte - deve ser "uma atitude" assumida por todos os profissionais de saúde que dela cuidam e não um rol de preceitos e ações a serem desempenhados por alguns profissionais em uma dada situação medicamente e formalmente determinada.

Entretanto, para poder cuidar da pessoa que morre, consideramos que seja necessário que o profissional de saúde compreenda e aprenda a lidar com seus próprios sentimentos de perda e medos frente à finitude da pessoa sob seus cuidados. Para tanto, estudos que abordem a perspectiva da pessoa que está vivenciando sua finitude nos mostram como ela deseja ser cuidada, possibilitando-lhe viver o que haja para viver, independente de quanto tempo tenha para isso. 


\section{Colaboradores}

JV Dolina realizou a coleta de dados, a análise destes e redigiu o artigo. R Bellato e LFS Araújo coordenaram a pesquisa matricial e foram as orientadoras do estudo, além de participarem da redação e revisão final.

\section{Referências}

1. Mufato LF, Araújo LFS, Bellato R, Nepomuceno MAS. (Re) organização no cotidiano familiar devido às repercussões da condição crônica por câncer. Ciênc Cuid Saúde 2012; 11(1):89-97.

2. Combinato DS, Queiroz MS. Morte: uma visão psicossocial. Estud psicol 2006; 11(2):209-216.

3. Kovács MJ. A morte em vida. In: Franco MHP, Kovács MJ, Carvalho MMMJ, Carvalho V, Organizadores. Vida e morte: laços da existência. 2a Edição. São Paulo: Casa do Psicólogo; 2011. p. 11-33.

4. Gomes AMA, Ruiz EN. Vida e morte no cotidiano: reflexões com o profissional da saúde. Fortaleza: EdUECE; 2006.

5. Bellato R, Carvalho EC. O jogo existencial e a ritualização da morte. Rev Latino-Am Enfermagem 2005; 13(1):99-104.

6. Siqueira KM, Barbosa MA, Boemer MR. O vivenciar a situação de ser com câncer: alguns desvelamentos. Rev. Lat Am Enfermagem 2007; 4(15):605-611.

7. Combinato DS, Queiroz MS. Um estudo sobre a morte: uma análise a partir do método explicativo de Vigotski. Cien Saude Colet 2011; 16(9):3893-3900.

8. Van velsen J. A análise situacional e o método de estudo de caso detalhado. In: Feldman-bianco B, organizador. Antropologia das sociedades contemporâneas: métodos. São Paulo: Unesp; 2010. p.345-375.

9. Minayo MCS. O desafio do conhecimento: pesquisa qualitativa em saúde. 12a Edição. São Paulo: Hucitec; 2010.

10. Bellato R, Araújo LFS, Faria APS, Santos EJF, Castro P, Souza SPS, Maruyama SAT. A história de vida focal e suas potencialidades na pesquisa em saúde e em enfermagem. Rev Eletr Enf 2008; 10(3):849-856.

11. Maffesoli M. O Conhecimento Comum: introdução à Sociologia Compreensiva. Porto Alegre: Sulina; 2007.

12. Lalanda P. Sobre a metodologia qualitativa na pesquisa. Rev Anál Social 1998; 33:871-883.

13. Morin E. A cabeça bem-feita: repensar a reforma, reformar o pensamento. 8a Edição. Rio de Janeiro: Bertrand Brasil; 2003.

14. Bellato R. A vivência da hospitalização pela pessoa doente [tese]. São Paulo (SP): Escola de Enfermagem de Ribeirão Preto; 2001.
15. Livio M. Razão Áurea: a história de Fi, um número surpreendente. 2a Edição. Rio de Janeiro: Record; 2007.

16. Cantinelli FS, Camacho RS, Smaletz O, Gonsales BK, Braguittoni E, Rennó JR. A oncopsiquiatria no câncer de mama: considerações a respeito de questões do feminino. Rev Psiquiatr Clín 2006; 33(3):124-133.

17. Bachelard G. A poética do espaço. São Paulo: Martins Fontes; 2008.

18. Barros PCM, Lima AO, Frej NZ, Melo MFV. Era uma casa ...!? Discurso, dinâmica familiar e contingências da rua. Psicol Estud 2009; 14(3):447-453.

19. Narvaz MG, Koller SH. Mulheres vítimas de violência doméstica: Compreendendo subjetividades assujeitadas. Psico 2006; 37(1):7-13.

20. Sontag S. Doença como metáfora. São Paulo: Companhia das Letras; 2007.

21. Molina MAS, Marconi SS. Mudanças nos relacionamentos com os amigos, cônjuge e família após o diagnóstico de câncer na mulher. Rev Bras Enferm 2006; 59(4):514-520.

22. Barreto TS, Amorim RC. A família frente ao adoecer e ao tratamento de um familiar com câncer. Rev Enf UERJ 2010; 18(3):462-467.

23. Kubler-ross E. Sobre a morte e o morrer. São Paulo: WMF Martins Fontes; 2008.

24. Guerrero GP, Zago MMF, Sawada NO, Pinto MH. Relação entre espiritualidade e câncer: perspectiva do paciente. Rev Bras Enferm 2011; 64(1):53-59.

25. Salci MA, Sales CA, Marcon SS. Sentimentos de mulheres ao receber o diagnóstico de câncer. Rev Enf UERJ 2009; 1(17):46-51.

Artigo apresentado em 30/04/2013

Aprovado em 22/05/2013

Versão final apresentada em 22/05/2013 